\title{
Kinetics Adsorption of Humic Acid from Water onto PVDF Nanofiber
}

\author{
Muhammad Ali Zulfikar, Irlin Afrianingsih, and Muhammad Nasir
}

\begin{abstract}
Humic acid (HA) is generally considered as one of ubiquitous pollutants in surface and ground water. In this study, the sorption of natural organic matter from water onto polyvinyl difluoride (PVDF) nanofiber under the influence of temperature has been investigated. The adsorption behaviors of the adsorbents for HA were investigated using batch experiments and adsorption kinetic tests. It was observed that the amount of HA adsorp increase with increasing temperature. The adsorption kinetic data of HA onto PVDF nanofiber was well described by a pseudo-second order model, with the kinetic constants in the range of $0.09-0.12 \mathrm{~g} \mathrm{mg}^{-1} \mathrm{~min}^{-1}$. From the intra-particle diffusion and Boyd kinetic models indicated that the HA adsorption process may be controlled by the intra-particle diffusion.
\end{abstract}

Index Terms-Adsorption, humic acid, nanofiber, PVDF.

\section{INTRODUCTION}

Humic acid (HA) is a component of natural organic matter (NOM) in surface and drinking water which arise by the microbial degradation of biomolecules. The existence of HA in drinking water, however, may lead to color, taste and odor problems, and to biological instability of drinking water in distribution system. Furthermore, HA is generally recognized as the major precursor of strongly carcinogenic disinfection byproducts (DBPs) formed during water treatment [1]-[5], which affect human health very seriously and can even cause cancer [5]. Therefore, the presence of HA in drinking water has been a great concern and measures have to be taken to minimize the presence of $\mathrm{HA}$ in drinking water and in other water resources.

Adsorption treatment has been considered as a simple and universal approach to effectively remove organic pollutants from the aquatic environment. Activated carbons (ACs) are the most widely used adsorbents for removing contaminants from wastewater because of its extended surface area, microporous structure, high adsorption capacity and high degree of surface reactivity [6], [7]. However the application of activated carbon is not always technically advantageous due to the high regeneration cost involved and the need to further dispose of the waste activated carbon. Thus, there is a need to continue the search and development of alternative adsorbents with high adsorptive capacity and low cost for HA

Manuscript received November 20, 2016; revised April 3, 2017. This work was supported in part by the Higher Education General under Grant Desentralisasi 2017.

M. A. Zulfikar is with the Analytical Chemistry Research Group, Institut Teknologi Bandung, Bandung, 40132 Indonesia (e-mail: zulfikar@chem.itb.ac.id). adsorption.

Nowadays, polymeric adsorbents have been increasingly used to remove and recover organic pollutants from wastewater due to their high specific area and high adsorption capacity. The materials can be made into nanofiber by electrospinning, which make it easy for regeneration. In this work, we investigated the effect of temperature on adsorption of HA from water onto polyvinyl difluoride (PVDF) nanofiber to be used as an adsorbent.

\section{MATERIALS AND METHOD}

\section{A. Materials}

PVDF nanofiber was obtained from Applied Chemistry Research Center, Indonesian Institute of Sciences, Indonesia. Humic acid (HA, humic acid sodium salts) was used as the HA source was purchased from Merck. Hydrochloric acid used to adjust $\mathrm{pH}$ was purchased from Merck. Water used was generated from aqua demineralization system. All materials were used without further purification. Before mixing the peat water sample with adsorbent, its $\mathrm{pH}$ value was adjusted and measured using 300 Hanna Instrument $\mathrm{pH}$ meter.

\section{B. Method}

Adsorption experiments were carried out in $100 \mathrm{~mL}$ flasks immersed in a thermostatic shaker bath at $25^{\circ} \mathrm{C}, 45^{\circ} \mathrm{C}, 65^{\circ} \mathrm{C}$ and $85^{\circ} \mathrm{C}$ in thermostatic shaker bath for $2,5,10,15,20,25$, $30,45,60,75$ and 90 minutes. PVDF nanofiber of $0.05 \mathrm{~g}$ were mixed with $50 \mathrm{~mL}$ of $\mathrm{HA}$ at $\mathrm{pH} 7$. At the end of the predetermined time interval, the mixture was taken out and the supernatant was sentrifugated. The HA concentrations before and after adsorption were determined by spectrophotometer (Shimadzu UV-Vis 1601 model) at the $\lambda$ $300 \mathrm{~nm}$. The percent of HA adsorption from peat water was calculated using the following equation:

$$
\operatorname{Removal}(\%)=\left[\left(C_{i}-C_{e}\right) / C_{i}\right] \times 100 \%
$$

where $C_{i}$ and $C_{e}$ are initial and final concentration of HA in solution, respectively. The adsorption capacity of an adsorbent at equilibrium with solution volume $V$, was calculated using the following equation:

$$
q_{e}\left(\mathrm{mg} \cdot \mathrm{g}^{-1}\right)=\left[\left(C_{i^{-}} C_{e}\right) / m\right] \times V
$$

where $C_{i}$ and $C_{e}$ are the initial and final concentration of HA in solution, respectively. $V$ is the volume of solution (L) and $m$ is mass of adsorbent $(\mathrm{g})$ used. 


\section{RESULTS AND DISCUSSION}

The effect of agitation time on adsorption of HA by PVDF nanofiber for different temperature are presented in Fig. 1. The percent adsorption of HA increased with increase in agitation time and reached equilibrium after $30 \mathrm{~min}$ for the each temperature used in this study.

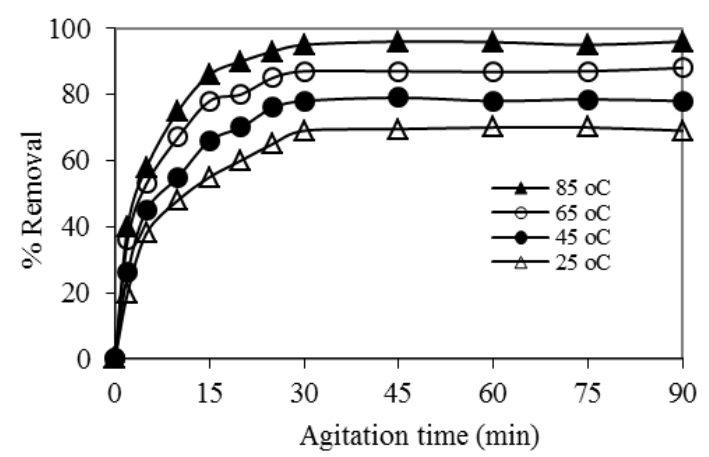

Fig. 1. Effect of temperature on HA adsorption.

As shown in Fig. 1, the amount of HA adsorbed using PVDF nanofiber increases with the increasing of temperature. This arises from the increase in the mobility of HA molecule with increasing temperature and more molecules across the external boundary layer and the internal pores of the adsorbent particles. Furthermore, increasing temperature may produce a swelling effect within the internal structure of the adsorbent enabling large HA to penetrate further [8]-[10].

The kinetic adsorption data were evaluated to understand the dynamics of the adsorption reaction in terms of the order of the rate constant. Batch experiments were conducted to explore the rate of HA adsorption by PVDF nanofiber as described in Section II.B at pH 7. Three kinetic models were applied to the adsorption kinetic data in order to investigate the behaviour of adsorption process of HA onto the absorbents. These models include the pseudo-first-order kinetics (reversible or irreversible), the pseudo-second-order and the intraparticle diffusion models. The linear form of reversible pseudo-first-order model can be formulated as:

$$
\log \left(q_{e}-q_{t}\right)=\log q_{e}-k / 2.303 . t
$$

where $q_{e}$ and $q_{t}$ are the amounts of organic compounds, (mg/g) adsorbed on sorbents at equilibrium, and at time $t$, respectively and $\mathrm{k}$ is the rate constant $\left(\mathrm{min}^{-1}\right)$. The rate $\mathrm{k}$ was obtained from slope of the linear plots of $\log \left(q_{e}-q_{t}\right)$ against $\mathrm{t}$. The linear form of pseudo-second-order equation can be formulated

as:

$$
t / q_{t}=1 / k_{2} \cdot q_{e}^{2}+t / q_{e}
$$

where $q_{e}$ and $q_{t}$ are surface loading of HA at equilibrium and time $t$ respectively, and $k_{2}(\mathrm{~g} / \mathrm{mgmin})$ is the second-order rate constant. The linear plot of $t / q_{t}$ as a function of $t$ provided not only the rate constant $k_{2}$, but also an independent evaluation of $q_{e}$.

As data after equilibrium does not influence the adsorption kinetics, experimental data before adsorption equilibrium were used to evaluate the adsorption kinetics. The plots of $\log$ $\left(q_{e}-q_{t}\right)$ versus $t$ based on pseudo-first-order kinetics and $t / q_{t}$ versus $t$ based on the pseudo-second-order kinetics are shown in Fig. 2 and 3, and the fitting parameters are listed in Table I.

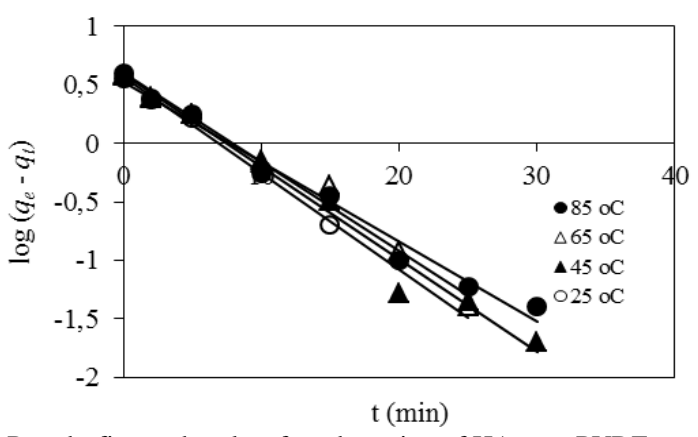

Fig. 2. Pseudo-first-order plots for adsorption of HA onto PVDF nanofiber.

As shown in Fig. 2, The plot of $\log \left(q_{e}-q_{t}\right)$ versus $t$ did not give a linear relation, suggesting that pseudo-first-order kinetic model cannot well describe HA adsorption process over PVDF nanofiber. Also from Table I, it is indicated that the values of the correlation coefficients are not high for the various temperatures solution. Furthermore, a large difference of equilibrium adsorption capacity $\left(q_{\mathrm{e}}\right)$ between the experiment and calculation was observed, indicating a poor pseudo-first-order fit to the experimental data. In contrast, the linear plots of $t / q_{t}$ versus $t$ with $R^{2}$ higher than 0.99 were obtained for HA adsorption to PVDF nanofiber (see Fig. 3).

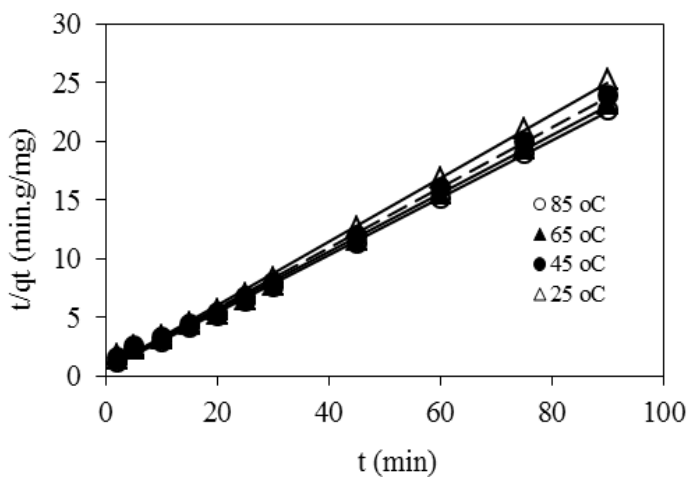

Fig. 3. Pseudo-second-order plots for adsorption of HA onto PVDF nanofiber.

TABLE I: KINETICS PARAMETERS FOR NOM ADSORPTION USING PVDF NANOFIBER

\begin{tabular}{ccccccc}
\hline \hline & \multicolumn{3}{c}{ Pseudo-first-orde } & \multicolumn{3}{c}{ Second-first-orde } \\
Temp. & $k_{1}$ & $q_{e}$ & $R^{2}$ & $k_{2}$ & $q_{e}$ & $R^{2}$ \\
$\left(\mathrm{~min}^{-1}\right)$ & $(\mathrm{mg} / \mathrm{g})$ & & $(\mathrm{g} / \mathrm{mgmin})$ & $(\mathrm{mg} / \mathrm{g})$ & \\
\hline 25 & 0.16 & 3.75 & 0.98 & 0.09 & 3.70 & 0.99 \\
45 & 0.17 & 3.86 & 0.97 & 0.10 & 3.91 & 0.99 \\
65 & 0.18 & 4.02 & 0.98 & 0.11 & 4.03 & 0.99 \\
85 & 0.19 & 3.44 & 0.97 & 0.12 & 4.10 & 0.99 \\
\hline \hline
\end{tabular}

In addition, HA adsorption amounts obtained from experimental data are approximately identical to those calculated from fitting results, further indicating that HA adsorption process obeys pseudo-second-order kinetics. As shown in Table I, the rate constants of HA adsorption to PVDF nanofiber were found to be $0.09,0.10,0.11$ and $0.12 \mathrm{~g}$ $\mathrm{mg}^{-1} \mathrm{~min}^{-1}$ at temperature of $25,45,65$ and $85^{\circ} \mathrm{C}$, respectively, indicative of a relatively higher adsorption process at higher temperature. The reason for this behavior can be attributed to 
the increase in the mobility of HA molecule with increasing temperature and consequently higher diffusion rates are obtained.

Considering that PVDF nanofiber is a porous adsorbent, diffusion in the pores may play an important role in HA adsorption over PVDF nanofiber. Therefore, Weber-Morris model is adopted to verify the controlling mechanism involved in HA adsorption process:

$$
q_{t}=k_{d} \cdot t^{1 / 2}+c
$$

where $k_{d}$ and $\mathrm{c}$ are intra-particle diffusion rate constant $\left(\mathrm{mg} / \mathrm{g} \cdot \mathrm{min}^{1 / 2}\right)$ and a constant, respectively. To follow the intra-particle diffusion model, a plot of $q t$ against $t^{1 / 2}$ should give a linear line where a slope is $k_{d}$ and intercept $\mathrm{c}$. Values of $\mathrm{c}$ give information regarding the thickness of boundary layer, i.e. the larger intercept the greater is the boundary layer effect [11]-[15].

The plots of qt versus $t^{1 / 2}$ with different temperature are presented in Fig. 4. The $q_{t}-t^{1 / 2}$ relations were found to be of multi-linearity before adsorption equilibrium, characteristic of multiple adsorption steps involved in the adsorption processes [11]-[15]. The plots were fitted using the linear regression method and the fitting parameters are listed in Table II. According to Weber-Morris model, the adsorption process is controlled predominantly by the intraparticle diffusion if the linear plot passing through the origin can be obtained. Alternatively, both the external diffusion and the intraparticle diffusion account for the global adsorption process provided the straight line deviates from the origin.

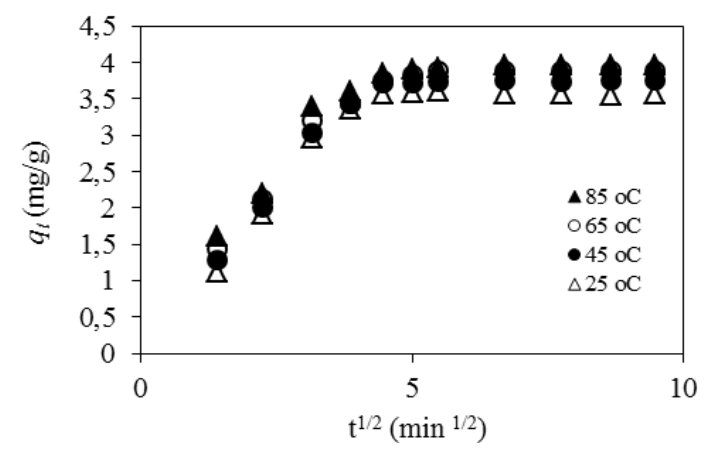

Fig. 4. Pseudo-second-order plots for adsorption of HA onto PVDF nanofiber.

As shown in Fig. 4, the $q_{t}-t^{1 / 2}$ plots consist of two linear portions for HA adsorption to PVDF nanofiber at different temperature and the extrapolation of the first linear portions $\left(k_{d 1}\right)$ does not pass through the origin, reflecting the existence of external mass transfer during HA adsorption processes. Considering that PVDF nanofiber is mesopore dominant, the first linear portion can be reasonably correlated to HA diffusion in the mesopores.

The second linear $\left(k_{d 2}\right)$ is a relatively slow adsorption region. This stage is a result of intra-particle diffusion effects [11]-[15], which is the rate-limiting step. The values of $k_{d l}$ and $k_{d 2}$ for the adsorption of HA slightly increased with increasing temperature from 25 to $85{ }^{\circ} \mathrm{C}$. This indicated that increasing temperature slightly increases the migration of HA into the inner structure of the PVDF nanofiber. From Table 2, we also can see that a larger interception of the first linear portion is obtained for HA adsorption at a higher temperature, resulting from the larger temperature gradient at initial diffusion stage. Furthermore, the larger interception at higher temperature is also indicative of a larger external mass transfer resistance [14].

TABLE II: KINETICS PARAMETERS OF THE INTRA-PARTICLE DIFFUSION FOR HA ADSORPTION USING PVDF NANOFIBER

\begin{tabular}{ccccc}
\hline \hline $\begin{array}{c}\text { Temp. } \\
\left({ }^{\circ} \mathrm{C}\right)\end{array}$ & $\begin{array}{c}k_{d l} \\
\left(\mathrm{mg} / \mathrm{g} \cdot \mathrm{min}^{1 / 2}\right)\end{array}$ & $C_{1}$ & $\begin{array}{c}k_{d 2} \\
\left(\mathrm{mg} / \mathrm{g} \cdot \mathrm{min}^{1 / 2}\right)\end{array}$ & $C_{2}$ \\
\hline 25 & 0.878 & -.0170 & 0.001 & 3.668 \\
45 & 0.823 & 0.018 & 0.003 & 3.758 \\
65 & 0.786 & 0.222 & 0.004 & 3.875 \\
85 & 0.745 & 0.345 & 0.007 & 3.912 \\
\hline \hline
\end{tabular}

In order to determine the actual rate controlling step involved in the HA adsorption process, the kinetic data as obtained by the batch method were further analyzed using the Boyd kinetics model. Boyd's kinetic model determines whether the main resistance to mass transfer is in the thin film (boundary layer) surrounding the adsorbent particle, or in the resistance to diffusion inside the pores. This model is expressed as:

$$
B_{t}=-0,4977-\ln (1-F)
$$

where $B_{t}$ is a mathematical function of $F$, and $F$ is the fraction of solute adsorbed at different times, $t(h)$, which is calculated as follows:

$$
F=q_{t} / q_{\alpha}
$$

where, $q_{\alpha}$ represents the amount sorbed $(\mathrm{mg} / \mathrm{g})$ at infinite time. The linearity of the plot of $B_{t}$ versus time is used to distinguish whether external (film diffusion) and intra-particle diffusion controls the adsorption rate [11], [12], [16].

A straight line passing through the origin is indicative of sorption processes governed by particle-diffusion (or pore diffusion) mechanisms. Otherwise they are governed by film diffusion or chemical reaction [16].

From the plot of $B_{t}$ against $t$ (Fig. 5), it was observed that the plots are linear with high correlation coefficient at all temperatures and pass through origin, confirming that particles diffusion is the rate-limiting step [16].

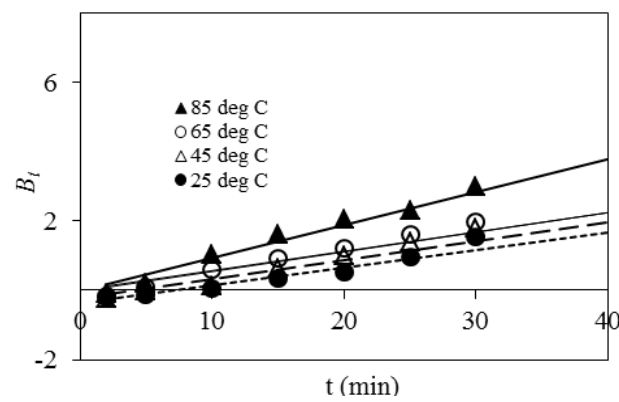

Fig. 5. Boyd kinetics model plots for adsorption of HA onto PVDF nanofiber.

\section{CONCLUSION}

The main aim of this study was to investigate the effect of temperature on HA adsorption using PVDF nanofiber as an adsorbent. The result from this work showed that the 
temperature has an important role in the adsorption of HA compounds onto PVDF nanofiber. The adsorption kinetics data of HA onto PVDF nanofiber was well described by a pseudo-second order model, with the kinetic constants in the range of $0.09-0.12 \mathrm{~g} \mathrm{mg}^{-1} \mathrm{~min}^{-1}$. From the intra-particle diffusion dan Boyd kinetic models indicated that the HA adsorption process may be controlled by the intra-particle diffusion.

\section{REFERENCES}

[1] J. C. Rojas, J. Pérez, G. Garralón, F. Plaza, B. Moreno, and M. A. Gómez, "Humic acids removal by aerated spiral-wound ultrafiltration membrane combined with coagulation-hydraulic flocculation," Desalination, vol. 266, pp. 128-133, 2011.

[2] C. S. Uygunera, S. A. Suphandaga, A. Kercb, and M. Bekbolet, "Evaluation of adsorption and coagulation characteristics of humic acids preceded by alternative advanced oxidation techniques," Desalination, vol. 210, pp. 183-193, 2007.

[3] D. Sonea, R. Pode, F. Manea, C. Ratiu, C. Lazau, I. Grozescu, and G. Burtica, "The comparative assessment of photolysis, sorption and photocatalysis processes to humic acids removal from water," Chemical Bulletin of "POLITEHNICA" Univ. (Timisoara), vol. 55, no. 69, pp. 148-151, 2010.

[4] C. Sun, Q. Yue, B. Gao, R. Mu, J. Liu, Y. Zhao, Z. Yang, and W. Xu, "Effect of $\mathrm{pH}$ and shear force on flocs characteristics for humic acid removal using polyferric aluminum chloride organic polymer dual-coagulants," Desalination, vol. 281, pp. 243-247, 2011.

[5] W.S. Ngah, S. Fatinathan, N.A. Yosop, "Isotherm and kinetic studies on the adsorption of humic acid onto chitosan- $\mathrm{H}_{2} \mathrm{SO}_{4}$ beads," Desalination, vol. 272, pp. 293-300, 2011.

[6] P.K. Malik, "Use of activated carbon prepared from sawdust and rice husk for adsorption of acid dyes: A case study of acid yellow 36," Dyes and Pigm., vol. 56, pp. 239-249, 2003.

[7] M. Toor and B. Jin, "Adsorption characteristics, isotherm, kinetics, and diffusion of modified natural bentonite for removing diazo dye," Chem. Eng. J., vol. 187, pp. 79-88, 2012.

[8] G. Mckay, "Adsorption of dyestuffs from aqueous solution with activated carbon: 1 : Equilibrium and batch contact time studies," $J$. Chem. Technol. Biotechnol., vol. 32, pp. 759-772, 1982.

[9] H. Hiroyuki, M. Fukudas, A. Okamato, and T. Kataoka, "Adsorption of acid dye cross linked chitosan fibers equilibria," Chem. Eng. Sci., vol. 48, no. 12, pp. 2267-2272, 1994.

[10] M. Saker, and S. Podar, "Study of adsorption of methyl violet onto flyash," in Proc. Ind. Annual Communication, 1994, vol. 31, pp. 213-215.
[11] M. A. Zulfikar and H. Setiyanto, "Study of the adsorption kinetics and thermodynamic for the removal of congo red from aqueous solution using powdered eggshell," Int. J. ChemTech. Res., vol. 5, no. 4, pp. 1671-1678, 2013

[12] M. F. Elkady, A. M. Ibrahim, and M. M. Abd El-Latif, "Assessment of the adsorption kinetics, equilibrium and thermodynamic for the potential removal of reactive red dye using eggshell biocomposite beads," Desalination, vol. 278, pp. 412-423, 2011.

[13] J. Fan, W. Cai, and J. Yu, "Adsorption of N719 dye on anatase $\mathrm{TiO}_{2}$ nanoparticles and nanosheets with exposed (001) facets: Equilibrium, kinetic, and thermodynamic studies," Chem. Asian J., vol. 6, pp. 2481-2490, 2011.

[14] J. Lin and Y. Zhan, "Adsorption of humic acid from aqueous solution onto unmodified and surfactant-modified chitosan/zeolite composites," Chem. Eng. J., vol. 200-202, pp. 202-213, 2012.

[15] M. A. Zulfikar, E. Novita, R. Hertadi, and S. D. Djajanti, "Removal of humic acid from peat water using untreated powdered eggshell as a low cost adsorbent," Int. J. Environ. Sci. Technol., vol. 10, pp. 1357-1366, 2013.

[16] X. J. Hu, J. S. Wang, Y. G. Liu et al., "Adsorption of chromium (VI) by ethylenediamine-modified cross-linked magnetic chitosan resin: Isotherm, kinetics and thermodynamics," J. Hazard. Mater. vol. 185 , pp. 306-314, 2011.

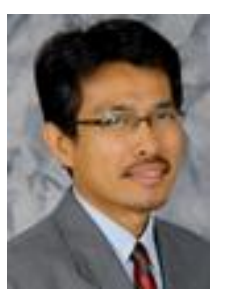

Muhammad Ali Zulfikar was born on 21 December, 1972 in Pekanbaru, Riau Province, Indonesia. He received undergraduate degrees in chemistry from the Institut Teknologi Bandung in 1996. His magister degrees was received from same institution in the field of analytical chemistry in 1999. In 2006, he receiving a doctorate in chemical and process engineering from National University of Malaysia.

After receiving a undergraduate degree, he became a lecturer and researcher at the Deaprtment of Chemistry, Institut Teknologi Bandung in the field Analytical Chemistry. He has made contributions to teaching courses on analytical chemistry, environmental chemistry, environmental analytical chemistry, forensic chemistry and capita selecta in analytical chemistry.

Dr. Muhammad Ali Zulfikar is now active doing research on material development that can be used as adsorbents. Some of his research has been published in international journals, such as International Journal of Environmental Science and Technology, Desalination and Water Treatment, Separation Science and Technology, etc. He also actively participates in national and international conferences. 